\title{
RE-DESIGN METERING SILO KELOMPOK 6 DI PT.X GUNA MENGURANGI BUFFERING
}

\author{
Deni Fajar Fitriyana ${ }^{1}$, , Sulardjaka ${ }^{1}$, Norman Iskandar ${ }^{1}$, Maulana Rizal ${ }^{1}$, M. Dzulfikar ${ }^{2}$ \\ ${ }^{1}$ Departemen Teknik Mesin, Fakultas Teknik, Universitas Diponegoro \\ Jl. Prof. H. Soedarto, Tembalang, Kota Semarang 50275. \\ ${ }^{2}$ Jurusan Teknik Mesin, Fakultas Teknik, Universitas Wahid Hasyim \\ Jl. Menoreh Tengah X/22, Sampangan, Semarang 50236 \\ *Email: deniifa89@gmail.com
}

\begin{abstract}
Abstrak
PT. X merupakan salah satu perusahaan rokok terbesar di Indonesia. PT. X melakukan peremajaan weight conveyor pada silo kelompok 6 karena memiliki debit yang kecil sehingga buffering berjalan cepat dan menyebabkan motor listrik panas akibat banyaknya on-off yang terjadi (121 kali), hal ini mengakibatkan metering silo kelompok 6 didesign ulang. Penelitian ini mempelajari tentang design ulang, mengetahui spesifikasi dan menghitung buffering pada metering silo kelompok 6 di PT. X. Langkah awal mendesign ulang metering yaitu mengetahui spesifikasi weight conveyor dan feeder conveyor, kemudian melakukan beberapa design metering menggunakan software Solidworks 2013 dan menganalisa aliran tembakau pada metering menggunakan ANSYS 15.0, setelah itu menghitung buffering metering yang terpilih. Hasil design ulang metering yaitu berbentuk balok dengan panjang $550 \mathrm{~mm}$, lebar $200 \mathrm{~mm}$, dan tinggi $1700 \mathrm{~mm}$ dengan ketebalan $2 \mathrm{~mm}$. Volume dari metering yaitu 0,187 $\mathrm{m}^{3}$ sedangkan luas selimutnya $1,6877 \mathrm{~m}^{2}$. Jumlah buffering selama 1 jam adalah 23,47 kali, jumlah ini $1 / 5$ dari jumlah buffering pada metering lama. Jadi, dengan jumlah buffering sebanyak 23,47 kali dapat meminimalisir panas berlebih pada motor listrik yang dapat menyebabkan kerusakan motor listrik.
\end{abstract}

Kata kunci : Buffering, Design, Metering, Re-design, Rokok.

\section{PENDAHULUAN}

Dalam proses pembuatan rokok terdapat beberapa proses utama yaitu proses perajangan, proses blending, dan proses packing. Pada proses blending terdapat komponen seperti feeder conveyor, metering, dan weight conveyor. Metering berfungsi sebagai wadah material setelah diangkutnya material tersebut dari feeder conveyor. Metering juga dapat mengatur buffering suatu material yang akan dilanjutkan menuju komponen selanjutnya yaitu weight conveyor. Buffering merupakan proses start fisnish dari feeder conveyor yang diakibatkan pada perbedaan debit antara feeder conveyor dan weight conveyor yang diatur oleh metering. Persamaan buffering dapat dimulai dengan persamaan berikut ini (Tippler, 1991):

$$
\mathrm{W}_{\mathrm{hm}}=\frac{\mathrm{v}_{\mathrm{j}}}{\mathrm{Q}_{\mathrm{w}}}
$$

Dimana :

$\mathrm{W}_{\mathrm{hm}}=$ Waktu menghabiskan volume jatuh volume sensor 2 metering (s)

$\mathrm{V}_{\mathrm{j}} \quad=$ Volume jatuh tembakau - sensor 2 metering $\left(\mathrm{m}^{3}\right)$

$\mathrm{Qw}=$ Debit weight conveyor $\left(\mathrm{m}^{3} / \mathrm{s}\right)$

$$
\dot{\mathrm{W}}_{p}=\frac{\mathrm{v}}{\mathrm{Q}_{c}}
$$

Dimana :

$\mathrm{W}_{\mathrm{p}}=$ Waktu pengisian volume sensor $2-3$ metering (s)

$\mathrm{V}=$ Volume sensor $2-3$ metering $\left(\mathrm{m}^{3}\right)$

$\mathrm{Q}_{\mathrm{c}} \quad=$ Debit conveyor $\left(\mathrm{m}^{3} / \mathrm{s}\right)$

$$
\mathrm{V}_{\mathrm{h}}=\mathrm{W}_{\mathrm{h}} \cdot \mathrm{Q}_{\mathrm{w}}
$$

Dimana :

$\mathrm{Vh} \quad=$ Volume hilang saat pengisian $\left(\mathrm{m}^{3}\right)$

$\mathrm{Wp}=$ Waktu pengisian volume sensor $2-3$ metering (s)

Qw $=$ Debit weight conveyor $\left(\mathrm{m}^{3} / \mathrm{s}\right)$

$$
\mathrm{W}_{\mathrm{hp}}=\frac{\mathrm{v}_{\mathrm{h}}}{\mathrm{Q}_{\mathrm{c}}}
$$

Keterangan :

$$
\begin{array}{lll}
\mathrm{W}_{\mathrm{hp}} & = & \begin{array}{l}
\text { Waktu volume yang hilang saat } \\
\text { pengisian }(\mathrm{s})
\end{array} \\
\mathrm{V}_{\mathrm{h}} & = & \begin{array}{l}
\text { Volume yang hilang saat } \\
\text { pengisian }\left(\mathrm{m}^{3}\right)
\end{array} \\
\mathrm{Q}_{\mathrm{c}} & = & \text { Debit conveyor }\left(\mathrm{m}^{3} / \mathrm{s}\right) \\
& \mathbf{T}_{\mathbf{w}}=\mathbf{W}_{\mathbf{p}}+\mathbf{W}_{\mathrm{hp}}
\end{array}
$$


Keterangan :

$\mathrm{T}_{\mathrm{w}} \quad=$ Total waktu pengisian (s)

$\mathrm{W}_{\mathrm{p}} \quad=$ Waktu pengisian volume sensor $2-3$ metering (s)

$\mathrm{W}_{\mathrm{hp}} \quad=$ Waktu volume yang hilang saat pengisian (s)

$$
\mathbf{T}_{\mathrm{b}}=\mathbf{T}_{\mathrm{w}}+\mathbf{W}_{\mathrm{hm}}
$$

Keterangan :

$\begin{array}{lll}\mathrm{T}_{\mathrm{b}}= & \begin{array}{l}\text { Total waktu buffering dalam } 1 \\ \text { siklus }(\mathrm{s})\end{array} \\ \mathrm{T}_{\mathrm{w}}= & \text { Total waktu pengisian }(\mathrm{s}) \\ \mathrm{W}_{\mathrm{hm}}= & \text { Waktu menghabiskan volume } \\ & & \begin{array}{l}\text { jatuh }- \text { volume sensor } 2 \text { metering } \\ (\mathrm{s})\end{array}\end{array}$

$$
\sum \mathrm{B}=\frac{3600 \mathrm{~s}}{\mathrm{~T}_{\mathrm{b}}}
$$

Keterangan :

$\sum \mathrm{B}=$ Jumlah buffering selama 1 jam.

$\mathrm{T}_{\mathrm{b}}=$ Total waktu buffering dalam 1 siklus (s)

Pada proses blending PT.X terdapat permasalahan pada silo kelompok 6 disebabkan oleh buffering. Lama buffering pada silo kelompok 6 sekitar 29 detik, dengan waktu yang begitu cepat mengakibatkan motor listrik on-off dengan banyak pula. Apabila terjadi dengan terus menerus akan mengakibatkan motor listrik cepat panas dan life-time pada motor listrik di feeder conveyor lebih rendah.

Tujuan penelitian ini melakukan design ulang metering, untuk mengurangi buffering metering silo kelompok 6 yang terdapat di PT. X. Analisa pengujian menggunakan program bantu ANSYS 15.0 dan dalam proses design dengan Solidworks 2013.

\section{METODE PENELITIAN}

Metering pada silo kelompok 6 di PT. X terbuat dari bahan stainless steels dengan ketebalan $2 \mathrm{~mm}$ dan berbentuk balok. Spesifikasi dari metering silo 6 dapat dilihat pada Tabel 1 seperti di bawah ini:

Tabel 1. Spesifikasi metering silo kelompok 6

\begin{tabular}{|lcc|}
\hline \multicolumn{1}{c}{ Items } & Besaran & Satuan \\
\hline Panjang & 0,36 & $\mathrm{~m}$ \\
Lebar & 0,13 & $\mathrm{~m}$ \\
Tinggi & 1,7 & $\mathrm{~m}$ \\
Ketebalan & 2 & $\mathrm{~mm}$ \\
Volume & 0,07956 & $\mathrm{~m}^{3}$ \\
Volume 2 - 3 & 0,00795 & $\mathrm{~m}^{3}$ \\
Kecepatan & 0,00826 & $\mathrm{~m} / \mathrm{s}$ \\
Luas Selimut & 0,96881 & $\mathrm{~m}^{2}$ \\
\hline
\end{tabular}

Sedangkan spesifikasi dari feeder conveyor dapat dilihat pada Tabel 2 di bawah ini :

Tabel 2. Spesifikasi feeder conveyor

\begin{tabular}{|lcc|}
\hline \multicolumn{1}{|c}{ Items } & Besaran & Satuan \\
\hline Kapasitas & 800 & $\mathrm{~kg} / \mathrm{jam}$ \\
Debit & 0,0694 & $\mathrm{~m}^{3} / \mathrm{menit}$ \\
\hline
\end{tabular}

Untuk spesifikasi dari weight conveyor ditunjukkan oleh Tabel 3 di bawah ini :

Tabel 3. Spesifikasi weight conveyor

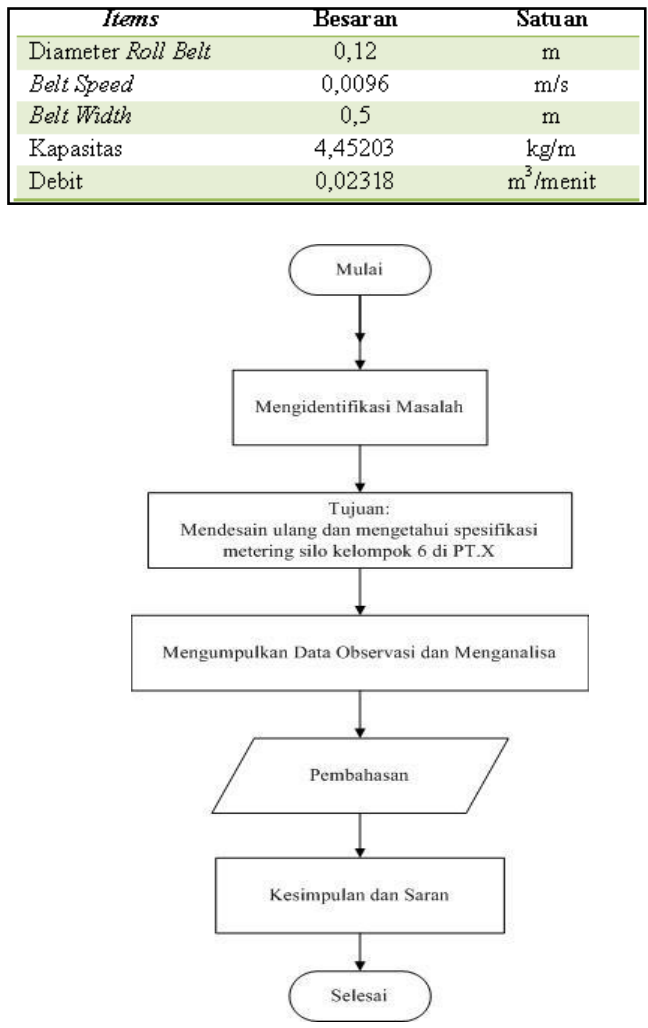

Gambar 1. Diagram alir pemecahan masalah

Metode yang digunakan :

1. Mengidentifikasi masalah

Masalah yang terjadi pada PT. X yaitu banyaknya buffering yang terjadi didalam metering silo kelompok 6. Sehingga PT.X melakukan peremajaan mesin.

2. Observasi dan analisa

Mengumpulkan data observasi dan menganalisa dilakukan dengan mengambil data dan melakukan pengamatan secara langsung di lapangan, kemudian melakukan analisa pada data observasi yang telah diperoleh di lapangan dengan bimbingan pekerja perusahaan.

3. Pembahasan

Dalam tahap ini semua hasil analisa dari data observasi dibahas sesuai parameter yang telah ditetapkan oleh perusahaan. Kemudian membuat 
beberapa pilihan konsep metering dengan bantuan software Solidworks 2013.

Untuk menggantikan metering yang lama, memilih konsep yang sesuai dengan kriteria perusahaan dan melakukan analisa pada metering konsep terpilih dengan bantuan software ANSYS 15.0

4. Kesimpulan dan saran

Kesimpulan dan saran digunakan untuk menyimpulkan apa yang sudah didapatkan dan memberikan saran kepada perusahaan agar menjadi lebih baik lagi kedepannya.

\section{HASIL DAN PEMBAHASAN}

Pada bagian ini akan dibahas hasil yang telah dicapai dan melakukan pembahasan masalah yang sudah diselesaikan.

\subsection{Data Lapangan}

Hasil perhitungan data lapangan ditunjukkan oleh Tabel 4 seperti di bawah ini :

Tabel 4. Hasil perhitungan metering di lapangan

\begin{tabular}{|lcc|}
\hline \multicolumn{1}{|c}{ Items } & Besaran & Satuan \\
\hline Waktu habis sensor 2- sensor 3 & 20,58 & $\mathrm{~s}$ \\
Waktu pengisian sensor 2 - sensor 3 & 6,87 & $\mathrm{~s}$ \\
Volume yang hilang selama pengisian & 0,00265 & $\mathrm{~m}^{3}$ \\
Waktu volume yang hilang saat pengisian & 2,295 & $\mathrm{~s}$ \\
Total waktu selama pengisian & 9,169 & $\mathrm{~s}$ \\
Total waktu buffering dalam 1 siklus & 29,756 & $\mathrm{~s}$ \\
Jumlah buffering selama 1 jam & 120,98 & kali \\
\hline
\end{tabular}

Dari perhitungan diperoleh jumlah buffering selama 1 jam pada metering lama sebanyak 120,98 kali. Jumlah sebanyak ini sama artinya motor listrik yang berfungsi menggerakkan feeder conveyor juga on-off sebanyak 120,98 kali per jam, dengan banyaknya on-off pada motor listrik sebanyak ini menyebabkan motor listrik menjadi panas dan dapat merusak motor listrik (Michaud, 2017).

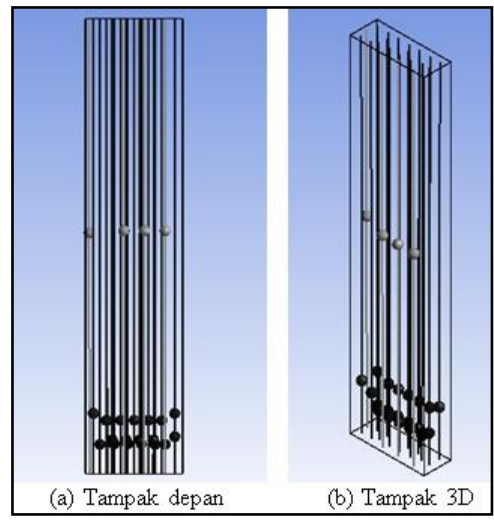

Gambar 2. Aliran tembakau pada metering lama
Gambar 2 menunjukan laju aliran tembakau pada metering lama yang berjalan dengan normal tanpa ada hambatan.

\subsection{Pilihan Konsep}

Pilihan konsep ini digunakan untuk membuat beberapa konsep metering yang akan dijadikan konsep terpilih (Ulrich dan Eppinger, 2001).

\subsubsection{Konsep pertama}

Konsep pertama yang ditawarkan dari design ini mempunyai bentuk seperti design metering yang lama namun berbeda pada dimensinya. Materialnya terbuat dari stainless steels, jarak dalam meletakkan sensor pun juga berbeda dengan yang lama. Tabel 5 menunjukkan spesifikasi dari metering konsep pertama.

Tabel 5. Spesifikasi metering konsep pertama

\begin{tabular}{|lcc|}
\hline \multicolumn{1}{|c}{ Items } & Besaran & Satuan \\
\hline Panjang & 0,55 & $\mathrm{~m}$ \\
Lebar & 0,20 & $\mathrm{~m}$ \\
Tinggi & 1,7 & $\mathrm{~m}$ \\
Ketebalan & 2 & $\mathrm{~mm}$ \\
Volume & 0,187 & $\mathrm{~m}^{3}$ \\
Volume 2 - 3 & 0,0605 & $\mathrm{~m}^{3}$ \\
Luas Selimut & 1,6877 & $\mathrm{~m}^{2}$ \\
\hline
\end{tabular}

Berdasarkan tabel 5, volume dan luas selimut konsep pertama lebih besar dari design yang lama. Hal ini menunjukkan plat stainless steels dalam pembuatan metering konsep pertama lebih banyak. Pada aliran tembakau yang mengalir pada metering konsep pertama berjalan secara sejajar sama seperti design yang lama. Gambar 3 menunjukkan analisa aliran tembakau pada metering konsep pertama menggunakan software ANSYS 15.0.

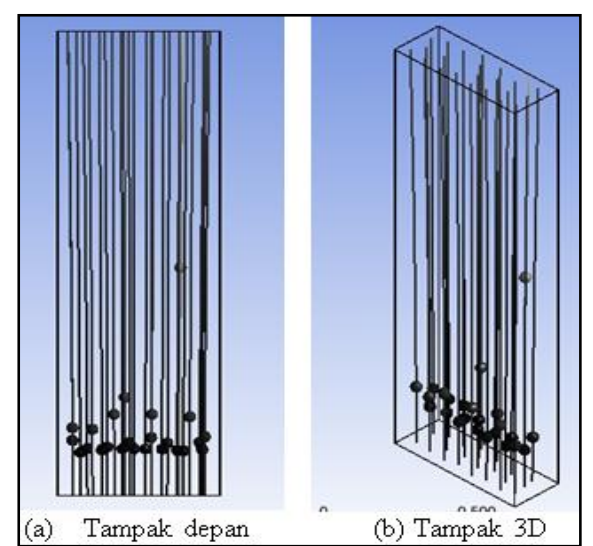

Gambar 3 Aliran tembakau pada metering konsep pertama 


\subsubsection{Konsep Kedua}

Konsep kedua yang ditawarkan dari design ini mempunyai bentuk tabung. Material yang dibuat masih sama yaitu stainless steels. Tabel 6 menunjukkan spesifikasi dari metering konsep kedua.

Tabel 6. Spesifikasi metering konsep kedua.

\begin{tabular}{|lcc|}
\hline \multicolumn{1}{|c}{ Items } & Besaran & Satuan \\
\hline Diameter & 0,55 & $\mathrm{~m}$ \\
Tinggi & 1,7 & $\mathrm{~m}$ \\
Ketebalan & 2 & $\mathrm{~mm}$ \\
Volume & 0,4038 & $\mathrm{~m}^{3}$ \\
Volume $2-3$ & 0,1306 & $\mathrm{~m}^{3}$ \\
Luas Selimut & 2,9359 & $\mathrm{~m}^{2}$ \\
\hline
\end{tabular}

Berdasarkan tabel 6 , volume dan luas selimut konsep kedua lebih besar dari konsep pertama dan design lama. Hal ini menunjukkan plat stainless steels dalam pembuatan metering konsep kedua lebih banyak. Pada aliran tembakau yang mengalir pada metering konsep kedua berjalan secara sejajar sama seperti design sebelumnya. Gambar 4 menunjukkan analisa aliran tembakau pada metering konsep kedua menggunakan software ANSYS 15.0.

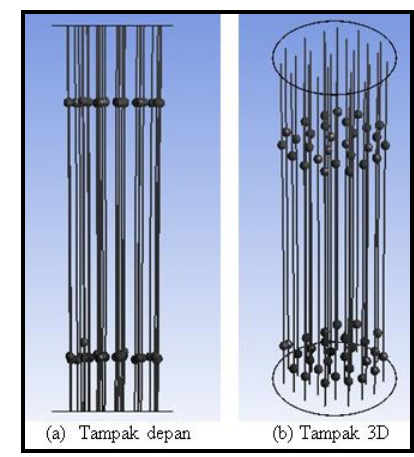

Gambar 4 Aliran tembakau pada metering konsep kedua

\subsubsection{Konsep Ketiga}

Konsep ketiga yang ditawarkan dari design ini mempunyai bentuk prisma segi empat. Material yang dibuat masih sama yaitu stainless steels. Tabel 7 menunjukkan spesifikasi dari metering konsep ketiga.

Tabel 7. Spesifikasi metering konsep ketiga.

\begin{tabular}{|lcc|}
\hline \multicolumn{1}{|c}{ Items } & Besaran & Satuan \\
Luas segi empat atas & $0,6 \times 0,3$ & $\mathrm{~m}^{2}$ \\
Luas segi empat bawah & $0,4 \times 0,2$ & $\mathrm{~m}^{2}$ \\
Tinggi & 1,7 & $\mathrm{~m}$ \\
Ketebalan & 2 & $\mathrm{~mm}$ \\
Volume & 0,2153 & $\mathrm{~m}^{3}$ \\
Volume 2-3 & 0,0696 & $\mathrm{~m}^{3}$ \\
Luas Selimut & 1,8993 & $\mathrm{~m}^{2}$ \\
\hline
\end{tabular}

Berdasarkan tabel 7, volume konsep ketiga lebih besar dari konsep pertama dan lebih kecil dari konsep kedua. Dari segi luas selimut, konsep ketiga lebih kecil dari konsep kedua dan lebih besar dari konsep pertama dan design lama. Pada aliran tembakau yang mengalir pada metering konsep ketiga berjalan secara sejajar dan lama lama membentuk jembatan atau bridging. Gambar 5 menunjukkan analisa aliran tembakau pada metering konsep ketiga menggunakan software ANSYS 15.0, pada gambar 5 terlihat tembakau membentuk bridging pada metering dengan design berbentuk prisma. Pembentukan bridging ini apabila terjadi pada metering PT. X bisa menghambat laju tembakau karena terjadi kompetisi saat tembakau akan keluar dari metering menuju weight conveyor (Michaud, 2017) (Cocco, 2017).

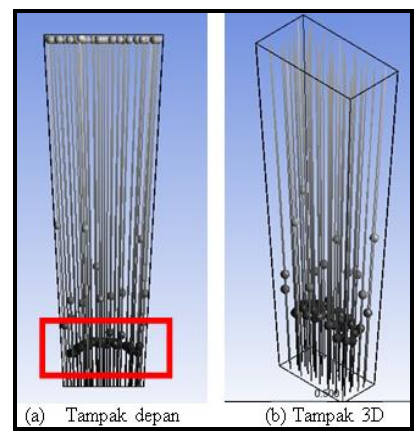

Gambar 5 Aliran tembakau pada metering konsep ketiga

\subsubsection{Konsep Terpilih}

Dari re-design metering terdapat kelebihan dan kekurangan dari masing - masing design. Tabel 8 menunjukkan bobot penilaian konsep re-design metering.

Tabel 8. Bobot penilaian konsep re-design metering.

\begin{tabular}{|c|c|c|c|}
\hline \multirow{2}{*}{ Design } & \multicolumn{3}{|c|}{ Parameter } \\
\cline { 2 - 4 } & $\begin{array}{c}\text { Pemasangan } \\
\text { Kaca }\end{array}$ & $\begin{array}{c}\text { Luas } \\
\text { Selimut }\end{array}$ & $\begin{array}{c}\text { Aliran } \\
\text { Tembakau }\end{array}$ \\
\hline $\mathbf{1}$ & Mudah & Kecil & Sejaj ar \\
\hline $\mathbf{2}$ & Sulit & Besar & Sejajar \\
\hline $\mathbf{3}$ & Mudah & Sedang & Bridging \\
\hline
\end{tabular}

Berdasarkan parameter yang sudah ditentukan, maka konsep re-design yang dipilih adalah konsep pertama karena pada konsep pertama memenuhi semua parameter yang sudah ditentukan dan lebih baik dari kedua konsep yang telah dibuat. Kemudian perhitungan buffering konsep terpilih dapat dilihat pada tabel 9 seperti di bawah ini.

Tabel 9. Hasil perhitungan konsep terpilih metering 


\begin{tabular}{|lcc|}
\hline \multicolumn{1}{|c}{ Items } & Besaran & Satuan \\
\hline Waktu habis sensor 2 - sensor 3 & 130,46 & $\mathrm{~s}$ \\
Waktu pengisian sensor 2 - sensor 3 & 16,89 & $\mathrm{~s}$ \\
Volume yang hil ang selama pengisian & 0,007835 & $\mathrm{~m}^{3}$ \\
Waktu volume yang hilang saat pengisian & 6,0177 & $\mathrm{~s}$ \\
Total waktu selama pengisian & 22,913 & $\mathrm{~s}$ \\
Total waktu buffering dal am 1 siklus & 153,37 & $\mathrm{~s}$ \\
Jumlah buffering selama 1 jam & 23,47 & kali \\
\hline
\end{tabular}

Sehingga dapat disimpulkan jumlah buffering selama 1 jam yaitu sebanyak 23,47 kali. Perbandingan jumlah buffering pada konsep pertama dengan metering lama yaitu 1:5. Hal ini menunjukkan bahwa dengan design metering baru dapat meminimalisir panas yang berlebihan pada motor listrik yang bisa menyebabkan kerusakan pada motor listrik.

\section{KESIMPULAN}

Dari hasil penelitian mengenai re-design metering silo kelompok 6 di PT. X didapatkan kesimpulan :

1. Terdapat beberapa alternatif konsep dalam mendesign metering silo kelompok 6 di PT. $\mathrm{X}$, tetapi konsep pertama yang dipilih karena memenuhi semua parameter yang sudah ditetapkan yaitu pemasangan kaca yang mudah, luas selimut plat yang tidak luas, laju aliran tembakau sejajar.

2. Hasil perhitungan jumlah buffering kosep terpilih selama 1 jam sebanyak 23,47 kali. Perbandingan jumlah buffering konsep terpilih dengan buffering metering lama adalah 1:5. Hal ini menunjukkan bahwa design konsep terpilih dapat meminimalisir panas berlebih pada motor listrik yang dapat menyebabkan kerusakan motor listrik. Oleh karena itu, semakin besar volume pada metering, semakin lama pula total waktu bufferingnya, namun jumlah buffering semakin sedikit jumlahnya.

\section{DAFTAR PUSTAKA}

Tippler. Paul A. 1991. Fisika Untuk Sains dan Teknik, Jakarta: Erlangga.

Ulrich, Karl T. \& Steven D. Eppinger. (2001). Perancangan \& Pengembangan Produk. Salemba Teknika, Jakarta.

Cocco, Ray. Powder bulk and Engineering. www.powderbulk.com. Diakses: 28 Juni 2017, jam 13.30.

Michaud, David. Type Of Material Flow Problem.www.911metallurgist.com. Diakses: 28 Juni 2017, jam 14.30. 